\title{
Distal landing zone optimization before endovascular repair of aortic dissection
}

\author{
Mel J. Sharafuddin, MD, FACS, , , Jay K. Bhama, MD, ${ }^{\text {a,c }}$ Mohammad Bashir, MD, ${ }^{\text {a,c }}$ \\ Maen S. Aboul-Hosn, MD, ${ }^{\mathrm{a}, \mathrm{b}}$ Jeanette H. Man, MD, ${ }^{\mathrm{a}, \mathrm{b}}$ and Alexandra J. Sharp ${ }^{\mathrm{a}}$
}

\begin{abstract}
Background: The general goals of endovascular management in chronic distal thoracic aortic dissection are optimizing the true lumen, maintaining branch patency, and promoting false lumen (FL) thrombosis. Distal seal can be challenging in chronic distal thoracic aortic dissection due to the well-established secondary fenestrations and fibrotic septum. We describe our approach of distal landing zone optimization (DLZO) to enable full-diameter contact of the distal endoprosthesis.
\end{abstract}

Materials and Methods: Our experience includes 19 procedures in 16 patients (12 male, age $68 \pm 8$ years) between May 2014 and November 2017. A history of previous ascending repair for type A dissection was present in 8 patients. Treatment indication was enlarging aneurysm in all subjects, and 4 patients had associated chronic visceral or distal ischemia. Point septal fenestrations were expanded by serial balloon dilation and/or wire-pull approaches. Balloon molding was used to ensure complete endograft apposition and FL collapse.

Results: One death occurred due to aortic perforation during wire-pull fenestration in a patient with heavily calcified and angulated aorta. The remaining procedures were accomplished safely and successfully. Balloon fenestration was used in 16 procedures, alone or in combination with a limited wire pull component. Adjunct procedures for distal seal included surgeon-modified fenestrated stent graft (3), iliac branch device (3), parallel superior mesenteric artery stent-graft (1), renal artery or superior mesenteric artery stent-graft (4), iliac stent (3), and plug obliteration of FL (5). Reintervention was required in 3 patients due to delayed loss of seal after the initial procedure (3, 8, and 12 months). Two were managed by repeat DLZO and distal extension. The third had distal extension via a surgeon-modified fenestrated stent-graft component. Follow-up imaging was available in 14 patients ( $16.0 \pm 12.5$ months, range: $1-33)$, with stable or regressed sac diameter with complete or near-complete thrombosis of the FL in all patients.

Conclusions: DLZO enabled creation of a distal seal zone in all patients. Residual retrograde filling of the FL is a marker of procedure failure, especially when seal segment length or feasible endoprosthesis oversizing are marginal. Insufficient landing segment can be circumvented with the use of a fenestrated or branched device to accomplish seal in the visceral aorta or iliac bifurcation. Adjunct FL ablation is also a valuable technique to promote FL thrombosis. (J Thorac Cardiovasc Surg 2019;157:88-98)

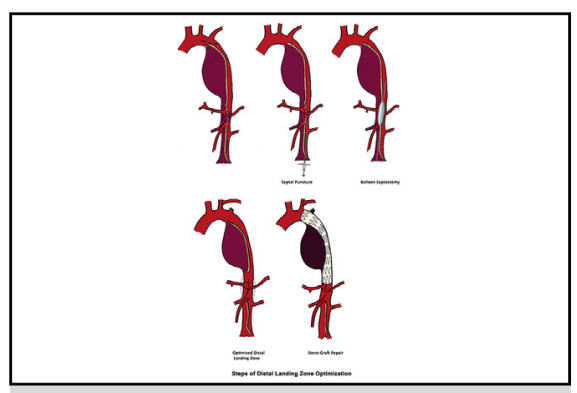

Decompartmentalization of the aorta at the intended distal landing zone enables treatment.

\section{Central Message}

Incomplete exclusion of aneurysmal pathology in chronic distal thoracic aortic dissection is often due to lack of distal seal. We describe our comprehensive approach of distal landing zone optimization (DLZO).

\section{Perspective}

Most failures of endovascular therapy in CDAD directly relate to persistent retrograde filling of the FL due to suboptimal or incomplete distal seal. Given the high morbidity of open repair in CDAD, less-morbid, hybrid approaches for distal seal zone optimization have been described, including open aortic fenestration or distal debranching procedures.

See Editorial Commentary page 99.
From the ${ }^{\mathrm{a}}$ Department of Surgery, ${ }^{\mathrm{b}}$ Division of Vascular Surgery, and ${ }^{\mathrm{c}}$ Division of Cardiothoracic Surgery, The University of Iowa Roy and Lucille Carver College of Medicine, Iowa City, Iowa.

Early experience was read, in part, at the Annual Winter Meeting of the Vascular \& Endovascular Surgery Society (VESS), Steamboat Springs, Colo, February 2017.

Read at The American Association for Thoracic Surgery Aortic Symposium 2018, New York, New York, April 26-27, 2018.

Received for publication March 28, 2018; revisions received June 8, 2018; accepted for publication June 24, 2018.

\footnotetext{
Address for reprints: Mel J. Sharafuddin, MD, FACS, Division of Vascular Surgery, Department of Surgery, The University of Iowa Roy and Lucille Carver College of Medicine, 200 Hawkins Dr, JCP1519, Iowa City, IA 52242 (E-mail: mel-sharafuddin@uiowa.edu). $0022-5223 / \$ 36.00$

Copyright (ㄷ 2018 by The American Association for Thoracic Surgery https://doi.org/10.1016/j.jtcvs.2018.06.095
} 

Abbreviations and Acronyms
ATBAD $=$ acute Stanford type-B aortic dissection
CDAD $=$ chronic distal thoracic aortic dissection
CTA = computed tomography angiography
DLZO = distal landing zone optimization
FL $\quad=$ false lumen
IVUS $=$ intravascular ultrasound
SMFSG $=$ surgeon-modified fenestrated stent graft
T1BEL $=$ type $1 \mathrm{~B}$ endoleak
$\mathrm{TL}=$ true lumen

Scanning this QR code will take you to a supplemental video for the article.

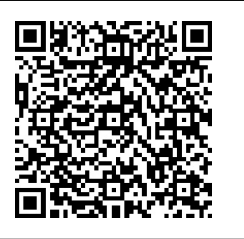

Patients with uncomplicated acute Stanford type B aortic dissection (ATBAD) generally have a good intermediateterm prognosis on optimal medical therapy, with mortality rates as low as $1 \%$ to $2 \%{ }^{1-3}$ Acute Stanford type A aortic dissection is typically managed operatively, with nearly two thirds of surviving patients left with a residual dissection component in the descending thoracic aorta. ${ }^{4-6}$ Surviving patients in both groups can be referred to collectively as chronic distal thoracic aortic dissections (CDADs). This diverse group of patients has in common a residual dissection of the descending thoracic and/or abdominal aorta, which is prone to aneurysmal degeneration over time..$^{5-9}$ Aneurysmal degeneration occurs in nearly $60 \%$ of surviving patients with ATBAD managed with optimal medical therapy and nearly one third of patients who undergo endograft repair in the acute/subacute phase., ${ }^{70}$ Long-term, intervention-free survival in CDAD is predominantly related to progressive aneurysmal degeneration, which mandates long-term radiographic surveillance to identify the subgroup of patients who may benefit from open or endovascular intervention. ${ }^{6,11-13}$

Open repair has long been considered the mainstay treatment modality in CDAD with progressive aneurysmal degeneration, ${ }^{14}$ although with the increasing experience with thoracic endovascular aortic repair and the high morbidity of open repair, endovascular therapy is increasingly becoming a preferred first-line therapy. ${ }^{15,16}$ However, stand-alone thoracic endovascular aortic repair in CDAD is plagued with unacceptable rates of failure, largely attributable to persistent retrograde filling and pressurization of the false lumen (FL), largely attributable to the lack of a suitable seal zone in the true lumen (TL) beyond the aneurysmal segment. Achieving proximal seal is generally straightforward with the availability of highly conformable endovascular devices and arch debranching techniques. Most failures are related to persistent retrograde filling of the distal FL. Distal debranching procedures and open septum fenestration may be used to provide distal landing zones. ${ }^{17-20}$ However, these approaches suffer from the high morbidity associated with open aortic and visceral surgery.

Over the past decade, we adopted an aggressive approach for the management of CDAD presenting with aneurysmal degeneration, centered on creating an optimized distal seal to enable exclusion of the aneurysmal segment, without compromising visceral or lower-extremity perfusion. The purpose of this retrospective study is to assess the efficacy and safety of this approach, which we term as distal landing zone optimization (DLZO).

\section{MATERIALS AND METHODS \\ Subjects Identification and Categorization}

We reviewed the electronic and imaging records of all patients who underwent an endovascular procedure in the setting of aortic dissections from August 2014 through November 2017. Sixteen patients were identified who underwent 19 procedures aimed at the creation and/or optimization of a distal landing zone to enable endovascular treatment of CDAD. This retrospective observational study was approved by our institutional review board, and informed consent was not required.

\section{Data Collection and Analysis}

The demographic, clinical, and anatomic data of patients considered for the study were collected retrospectively and are summarized in Tables 1-3. Statistical comparisons were made via the Fisher exact test for categorical variables and $t$ test for continuous variables. Statistical analysis was performed with SYSTAT 13 software (SPSS Inc, Chicago, Ill)

\section{Procedural and Technical Details}

Our experience with DLZO during the study period is more representative of a continuous evolution rather than a monolithic technique. The concept of DLZO is based on obliterating the septum between the TL and FL at the intended distal landing zone, allowing the distal end of a properly sized endograft to accomplish seal (Figure 1). DLZO may be combined with a proximal seal zone optimization procedure, such as subclavian-carotid transposition or bypass; however, specific details of the proximal adjunct procedures will not be detailed in this report.

Intravascular ultrasound (IVUS) was routinely used for TL and visceral branch mapping during all procedures. Fenestration of the dissection septum represents the key first step in DLZO. If present, native fenestrations in the septum can be used for the DLZO procedure. The native fenestration is enhanced through serial balloon dilatation as described to follow. When a native fenestration is not present in the desired location, a sharp fenestration is created through a needlebased point fenestration under either IVUS or fluoroscopic guidance. Some form of IVUS guidance during needle puncture was used in 9 procedures. However, fluoroscopic guidance of the puncture was used in the remaining procedures via a variety of methods, such as plain 
TABLE 1. Summary of demographic, anatomic, and clinical characteristics of 16 patients with CDAD included in the study

\begin{tabular}{|c|c|c|c|c|}
\hline Patient no. & $\begin{array}{c}\text { Demographic } \\
\text { Age, y, sex }\end{array}$ & Comorbidities & Presenting dissection type & Procedure date (2014-2017) \\
\hline \multicolumn{5}{|c|}{ Primary procedures } \\
\hline 1 & $64, \mathrm{M}$ & HTN, HLP, CKD-4 & A & August 14 \\
\hline 2 & $71, \mathrm{M}$ & HTN, HLP, tobacco, CAD, COPD & B & May 15 \\
\hline 3 & $60, \mathrm{M}$ & HTN, tobacco & A & May 15 \\
\hline 4 & $62, \mathrm{~F}$ & HTN, HLP, tobacco, CAD & A & May 15 \\
\hline 5 & $77, \mathrm{~F}$ & HTN, DM, HLP, tobacco, CAD, CKD-3 & B & January 16 \\
\hline 6 & $71, \mathrm{M}$ & HTN, CKD-2, A. fib & A & July 16 \\
\hline 7 & $68, M$ & HTN, HLP & B & October 16 \\
\hline 9 & $63, \mathrm{M}$ & HTN, HLP, CAD & B & December 16 \\
\hline 8 & $61, \mathrm{M}$ & HTN, HLP, tobacco, CAD, COPD & B & December 16 \\
\hline 10 & $58, \mathrm{M}$ & HTN, DM, tobacco, CKD & B & February 17 \\
\hline 11 & $62, \mathrm{~F}$ & HTN, DM, HLP, tobacco, CAD, CKD-4 & B & May 17 \\
\hline 12 & $79, \mathrm{~F}$ & HTN, HLP, tobacco, CAD, PVD, CKD-4 & A & July 17 \\
\hline 13 & $82, \mathrm{M}$ & HTN, HLP, tobacco, CAD & A & August 17 \\
\hline 14 & $54, \mathrm{M}$ & HTN, HLP, tobacco, CKD-4 & B & October 17 \\
\hline 16 & $70, \mathrm{M}$ & HTN, HLP, tobacco, CAD & B & October 17 \\
\hline 15 & $66, \mathrm{~W}$ & HTN, HLP, tobacco, PVD, CKD-4 & B & November 17 \\
\hline 17 & $70, \mathrm{~F}$ & HTN, HLP, CKD-3 & B & December 17 \\
\hline \multicolumn{5}{|l|}{ Reinterventions } \\
\hline 1 & & & & June 16 \\
\hline 2 & & & & June 16 \\
\hline 3 & & & & November 17 \\
\hline
\end{tabular}

$C D A D$, Chronic distal thoracic aortic dissection; $M$, male; $H T N$, hypertension; $H L P$, hyperlipidemia; $C K D$, chronic kidney disease; $C A D$, coronary artery disease; $C O P D$, chronic obstructive pulmonary disease; $F$, female; $D M$, diabetes mellitus; $A$. Fib, atrial fibrillation; $P V D$, peripheral vascular disease.

radiographic landmarks based on previous cross-sectional imaging studies or active fluoroscopic guidance using a snare or a contrastfilled balloon placed in the opposite lumen as a target for transseptal needle puncture.
Needle puncture was performed, as described previously, ${ }^{21}$ using a 65-cm long, 21-gauge biopsy needle (Chiba; Cook, Bloomington, Ind), coaxially loaded through a directional metallic cannula (Rösch-Uchida Transjugular Liver Access Set; Cook). Transseptal access was maintained

TABLE 2. Summary of indication and presentation delay since initial episode in 16 patients with CDAD included in the study

\begin{tabular}{|c|c|c|c|c|}
\hline $\begin{array}{l}\text { Months since initial } \\
\text { acute presentation }\end{array}$ & $\begin{array}{l}\text { Months since } \\
\text { type A repair }\end{array}$ & $\begin{array}{c}\text { Months since } \\
\text { type B presentation }\end{array}$ & $\begin{array}{c}\text { Months since } \\
\text { stand-alone TEVAR }\end{array}$ & $\begin{array}{l}\text { Treatment indication } / \mathrm{max} \text { combined } \\
\text { diameter, } \mathbf{m m}\end{array}$ \\
\hline 26 & 26 & & & Aneurysmal degeneration/60 \\
\hline 51 & . & 51 & & Aneurysmal degeneration/65 \\
\hline 75 & 75 & & & Aneurysmal degeneration/67 \\
\hline 174 & 174 & & & Aneurysmal degeneration/60 \\
\hline 1 & . & 1 & & Visceral ischemia/36 \\
\hline 61 & 61 & & & Aneurysmal degeneration/60 \\
\hline 33 & & 33 & & Aneurysmal degeneration/63 \\
\hline 80 & & 80 & & Aneurysmal degeneration/62 \\
\hline 44 & & 40 & & Aneurysmal degeneration-growth/75 \\
\hline 4 & & 4 & & Aneurysmal degeneration-growth/65 \\
\hline 1 & & 1 & & Rupture/visceral ischemia/43 \\
\hline 82 & 82 & & 103 & Aneurysmal degeneration-growth 7.0 \\
\hline 13 & 13 & & & Aneurysmal degeneration-growth/70 \\
\hline 36 & & 36 & & Aneurysmal degeneration-growth/75 \\
\hline 11 & & 11 & 6 & Aneurysmal degeneration-growth/60 \\
\hline 24 & & 24 & 19 & Visceral ischemia/39 \\
\hline \multirow[t]{4}{*}{1} & & 1 & & Rupture-visceral ischemia/45 \\
\hline & & & & T1BEL aneurysm growth/72 \\
\hline & & & & T1BEL aneurysm growth/65 \\
\hline & & & & T1BEL, aneurysm growth/7.0 \\
\hline
\end{tabular}


TABLE 3. Summary of pertinent procedural details in 16 patients with CDAD included in the study

\begin{tabular}{|c|c|c|c|}
\hline DLZO zone & DLZO details & $\begin{array}{l}\text { Stent-graft distal } \\
\text { diameter, } \mathbf{m m}\end{array}$ & $\begin{array}{l}\text { Spinal } \\
\text { drain }\end{array}$ \\
\hline DTA & Needle puncture, wire pull, balloon augmentation & 34 & 1 \\
\hline VISC & Needle puncture, wire pull & 42 & 1 \\
\hline DTA & Native fenestration, balloon augmentation & 38 & 1 \\
\hline VISC & Needle puncture, balloon augmentation & 40 & 1 \\
\hline VISC & Needle puncture, balloon augmentation & 32 & 0 \\
\hline VISC & Needle puncture, wire pull, balloon augmentation & 46 & 1 \\
\hline ILIAC & Needle puncture, wire pull, balloon augmentation, IBE, FL plug, other & 26 & 0 \\
\hline VISC & Needle puncture, balloon augmentation, SMFSG, FL plug & 32 & 1 \\
\hline VISC & $\begin{array}{l}\text { Native fenestration, balloon augmentation, IBE, infrarenal aortic relining, parallel visceral } \\
\text { stent-graft, FL plug }\end{array}$ & 34 & 1 \\
\hline VISC & Needle puncture, wire pull, balloon augmentation, bilateral IBE, infrarenal aortic lining & 28 & 0 \\
\hline DTA & Native fenestration, balloon augmentation & 31 & 0 \\
\hline DTA & Needle puncture, wire pull, balloon augmentation, SMFSG & 30 & 1 \\
\hline VISC & Needle puncture, wire pull, balloon augmentation & 40 & 1 \\
\hline DTA & Needle puncture, wire pull, balloon augmentation & 38 & 0 \\
\hline DTA & Needle puncture, balloon augmentation, FL plug & 40 & 0 \\
\hline VISC & Needle puncture, wire pull, balloon augmentation & 30 & 1 \\
\hline DTA & Needle puncture, balloon augmentation & 30 & 1 \\
\hline DTA & Needle puncture, wire pull, balloon augmentation & 38 & 1 \\
\hline DTA & Needle puncture, balloon augmentation & 34 & 1 \\
\hline VISC & Needle puncture, balloon augmentation, SMFSG, FL plug & 32 & 0 \\
\hline
\end{tabular}

$\overline{D L Z O}$, Distal landing zone optimization; $D T A$, distal thoracic aorta; $V I S C$, visceral aorta; $I L I A C$, iliac artery; $I B E$, iliac branch device; $F L$, false lumen; SMFSG, surgeon-modified fenestrated stent graft.
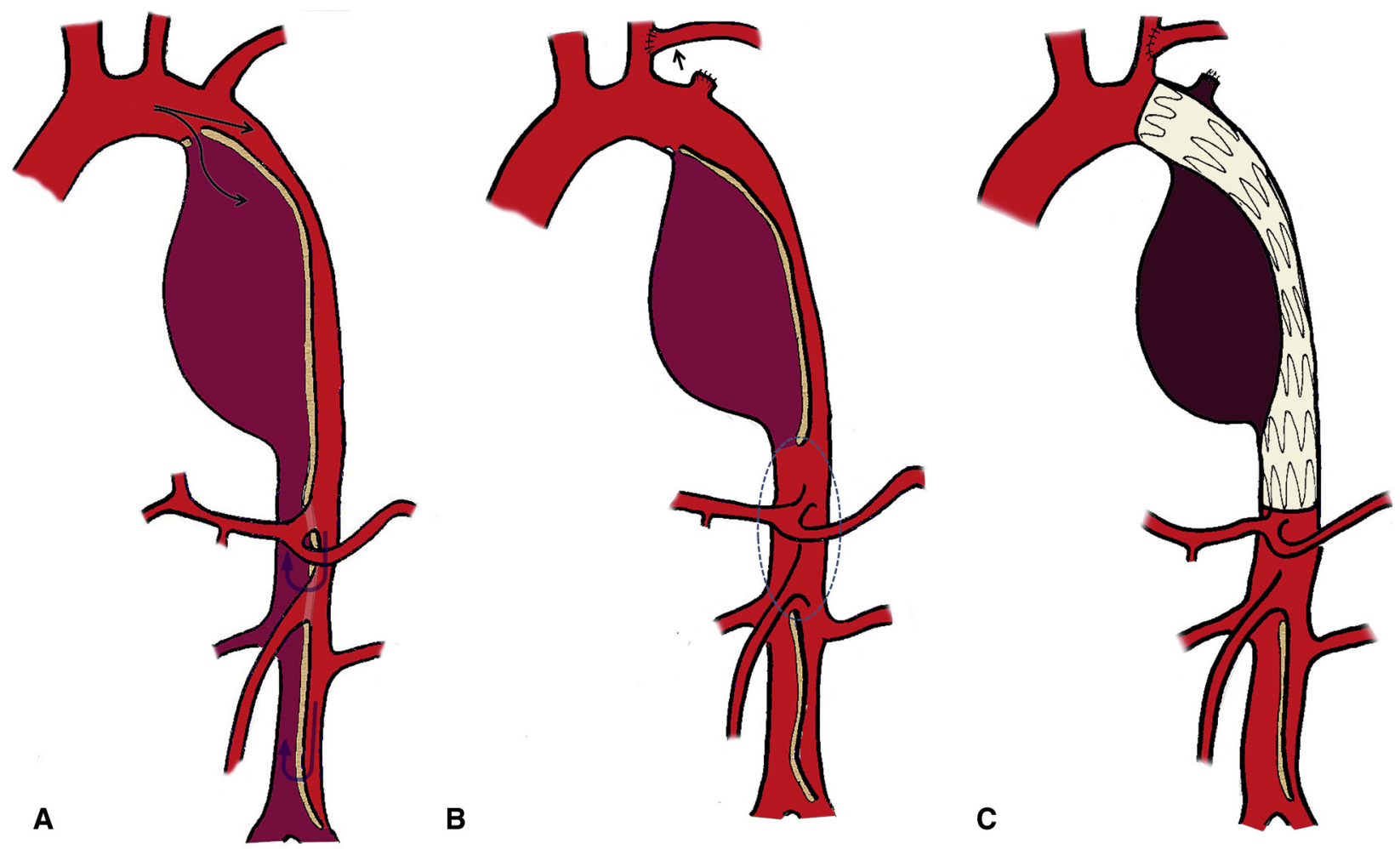

FIGURE 1. DLZO to enable exclusion of FL aneurysm in CDAD. A, CDAD with aneurysmal degeneration of the FL. Stand-alone endograft deployment in the TL will likely be associated with persistent retrograde filling of the FL (hairpin arrows). B, DLZO is performed at the levels of the visceral and supravisceral aorta (dashed oval). Proximal seal zone optimization was also accomplished with subclavian-carotid transposition (short arrow). C, Endograft deployment with balloon molding to allow the distal end the endograft to accomplish seal. 


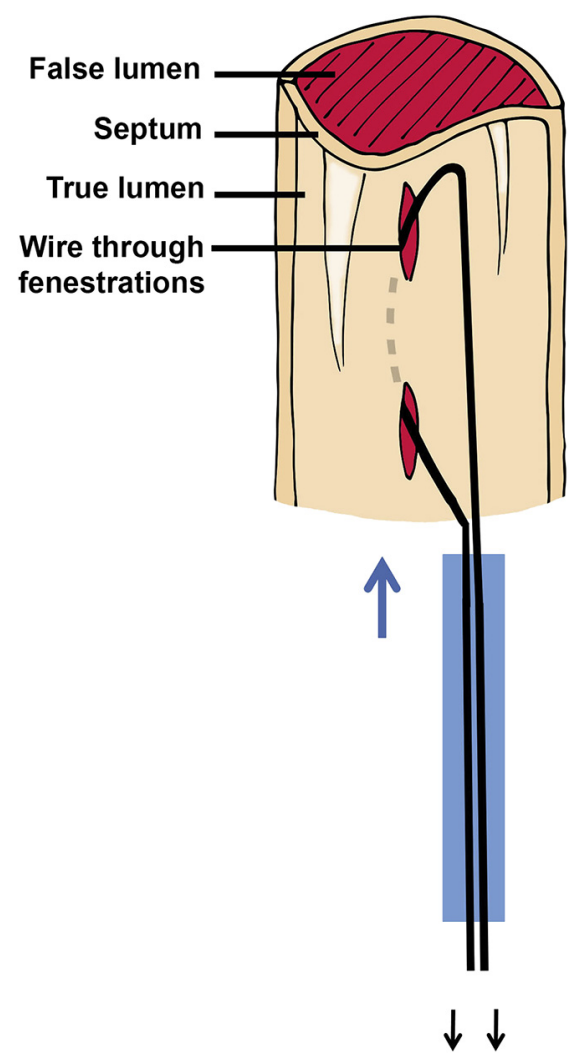

FIGURE 2. "Squeegee" wire fenestration technique. Essentially a controlled version of "cheese cutter" wire-pull fenestration. Two adjacent point fenestrations are placed at the desired location in the intended distal landing zone. The fenestrations are balloon dilated and a thin, kink-resistant guide wire is snared across the intervening septum between the 2 point fenestrations through a common sheath or guide catheter. The sheath or catheter is then advanced over the 2 wires (blue forward arrow) while firm pulling force is applied to the 2 ends of the wire (black arrows). A controlled wire slicing effect is produced by incrementally synching the septum between the 2 point fenestrations into a coalesced large fenestration.

with a 0.018 " kink-resistant guidewire (Nitrex; Medtronic, Minneapolis, Minn).

Once communication between the TL and FL is established, augmentation of the point-fenestration can be accomplished using 1 of 2 techniques: balloon fenestration or wire pull slicing. Balloon-based point fenestration consists of sequential dilatation of the initial point fenestration, first using a small balloon ( $4-10 \mathrm{~mm}$ ), followed by dilation up to the goal diameter using a large-vessel (20-25 mm) balloon (Z-MED II; B. Braun Medical, Bethlehem, Pa, or Edwards Balloon Catheter; Edwards Lifesciences, Irvine, Calif). Alternatively, a large compliant balloon (Coda; Cook) can be used, with caution taken to avoid overdilation. An approach of multiple adjacent/coalescent point fenestrations can also be used to expand the fenestration if large-diameter dilation is felt risky but will require additional adjacent septal fenestrations.

Wire-pull fenestration, sometimes referred to as "cheese cutter" fenestration, is performed by snaring a transseptal guidewire and pulling the 2 ends down while performing a see-saw motion with the 2 ends of the wire to produce a slicing effect. While generally effective, this approach suffers from lack of control and the risk of aortic wall injury when the maneuver is performed in a diseased or calcified aorta, especially across tortuous anatomy. Wire pull fenestration should also be avoided in acute dissections because of the high risk of intimal sloughing and bunching, which can result in an occlusive filling defect. We have evolved a wirepull modification that we call "Squeegee" wire fenestration, which is essentially a blend of the wire-pull and balloon fenestration, with the advantage of enhanced control and safety while maximizing the diameter of the resulting fenestration (Figure 2).

Once the distal landing zone has been optimized, the endograft is landed in an accurate manner to ensure that it straddles the fenestrated septum. Finally, balloon molding of the endograft is essential to sufficiently expand the endograft onto the optimized landing zone, to overcome the rigid septal remnants (Figure 3, Video 1). In patients in whom sufficient distal seal necessitated landing the endograft in the visceral aorta or beyond the iliac bifurcation, the following approaches were used: (1) patient anatomy-specific, surgeon-modified fenestrated stent graft (SMFSG) based on either thoracic or abdominal endograft platform (Alpha, TX2, or Zenith Flex; Cook), (2) parallel graft using antegrade snorkel branch for visceral incorporation (VIABAHN; GORE, Flagstaff, Ariz, or FLUENCY; Bard Peripheral Vascular, Tempe, Ariz), or (3) iliac branch device (IBE; Gore).

\section{RESULTS}

The study population consisted of 12 male and 4 female patients (mean age: $68.2 \pm 8.2$ years) who underwent DLZO before endovascular repair of CDAD between May 2014 and November 2017. The baseline etiology of chronic distal aortic dissection was TBAD in 11 patients and TAAD in 5 patients. Mean delay from the initial acute presentation and the DLZO procedure was $43.2 \pm 45.2$ months for the entire group. Mean delay from TBAD presentation was $32 \pm 33$ months (range: 1-103), whereas mean delay from TAAD was $70 \pm 63$ months (range: 13-174). Cerebrospinal fluid drainage beginning prior to the procedure was performed in 13 procedures. Two patients had a previous endovascular stent-graft repair procedure to seal the proximal entry point (6 months previously in a patient with CDAD and 103 months previously in a patient with ATBAD).

Indications for treatment in our patient population included the following: aneurysm diameter $\geq 55 \mathrm{~mm}$ in male patients or $\geq 50 \mathrm{~mm}$ in female patients, accelerated aneurysm growth ( $\geq 5 \mathrm{~mm}$ in 6 months), visceral or lower-extremity ischemia (4), and other acute presentations such as severe pain (2) or rupture (2).

Technical aspects, perioperative outcomes, and followup data are summarized in Tables 1 to 3 . The anatomic location of the distal-most extent of the optimized distal landing zone was the distal thoracic aorta in 7 patients, visceral aorta in 9 , and the infrarenal aortoiliac segments in 3 patients. DLZO was successfully accomplished in all patients. Balloon-assisted point fenestration was used in 16 procedures, alone or in combination with a limited wire pull component. Transseptal access was established using a sharp puncture approach using a coaxial directional needle system in 15 procedures. In 3 procedures, a native fenestration was catheterized to provide wire access over which balloon dilation was performed. 

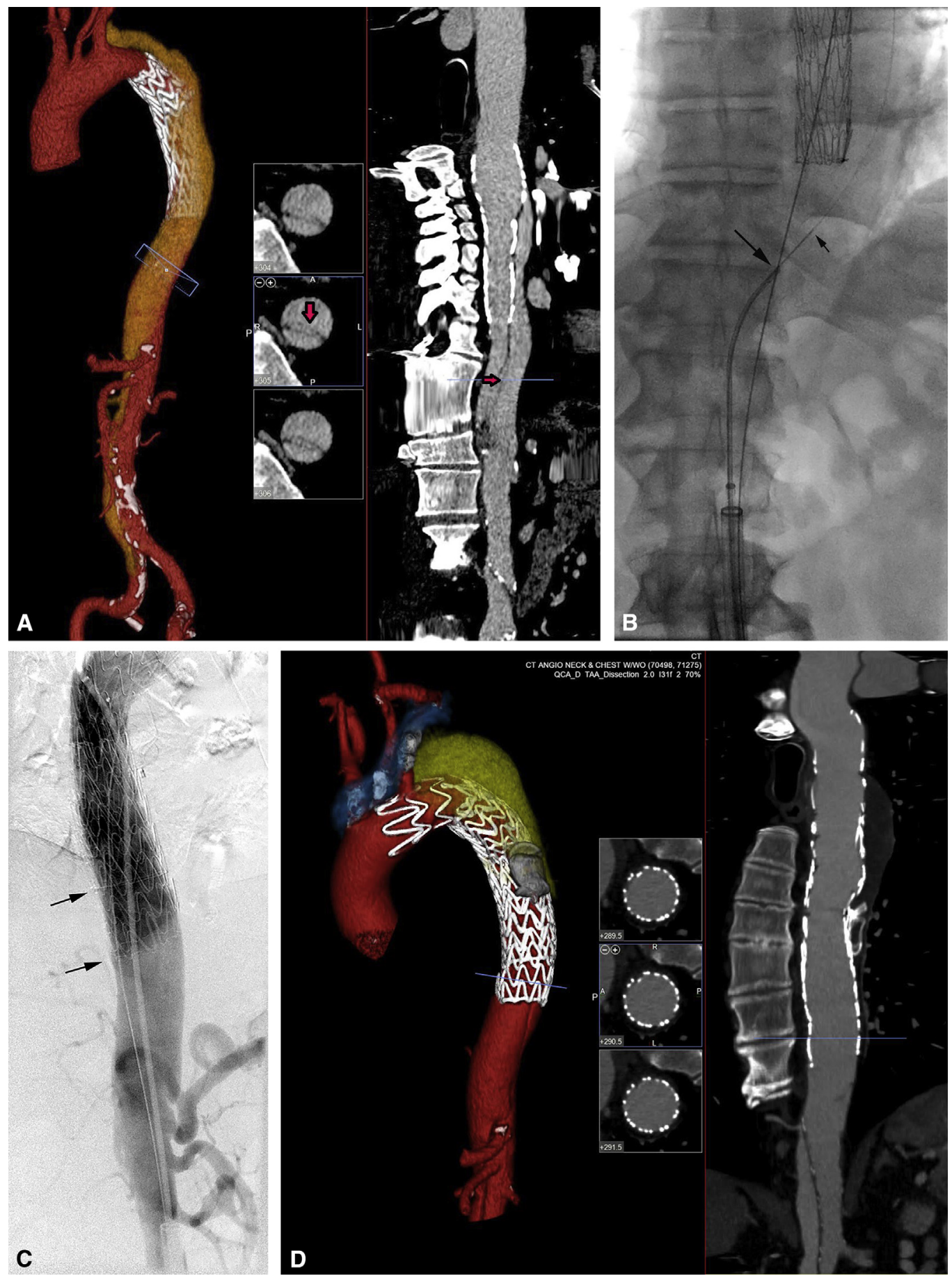

FIGURE 3. DLZO to enable distal seal before endograft exclusion of FL aneurysm in a patient with CDAD and progressive degeneration. A, A 68-year-old man with a history of endovascular aortic repair of ATBAD with coverage of the primary proximal tear 6 months previously presenting with back pain and enlarging FL aneurysm. CTA shows persistent retrograde filling of the FL via multiple re-entry points at the levels of the distal thoracic and visceral aorta. A distinct fibrotic septum is present (arrow), extending across the entire thoracoabdominal aorta into the iliac bifurcation, which precludes adequate exclusion of the aneurysm with stand-alone endograft deployment in the TL. Distal end of the stent-graft remains confined to the TL and has not fully expanded. B, Sharp puncture across the septum using a Chiba microneedle (short arrow) guided through a directional metallic cannula (long arrow). A 0.018 " nitinol guide wire is passed to establish access into the FL. Serial balloon dilatation was performed beginning with a 6-mm microballoon. The microwire was exchanged for a heavy-duty 0.035 " guide wire over which definite large balloon fenestration was performed. C, Final appearance after DLZO and distal extension using a CTAG endoprosthesis (GORE) (arrows), and an adjunct FL occlusion using a large vascular plug. Balloon molding was needed to overcome the septal remnants and ensure complete apposition of the stent-graft to the optimized aortic wall. D, Follow-up CTA 3 months later demonstrating complete thrombosis of the FL with good distal seal. Also seen is the AMPLATZER plug that was placed in the FL to promote thrombosis. 


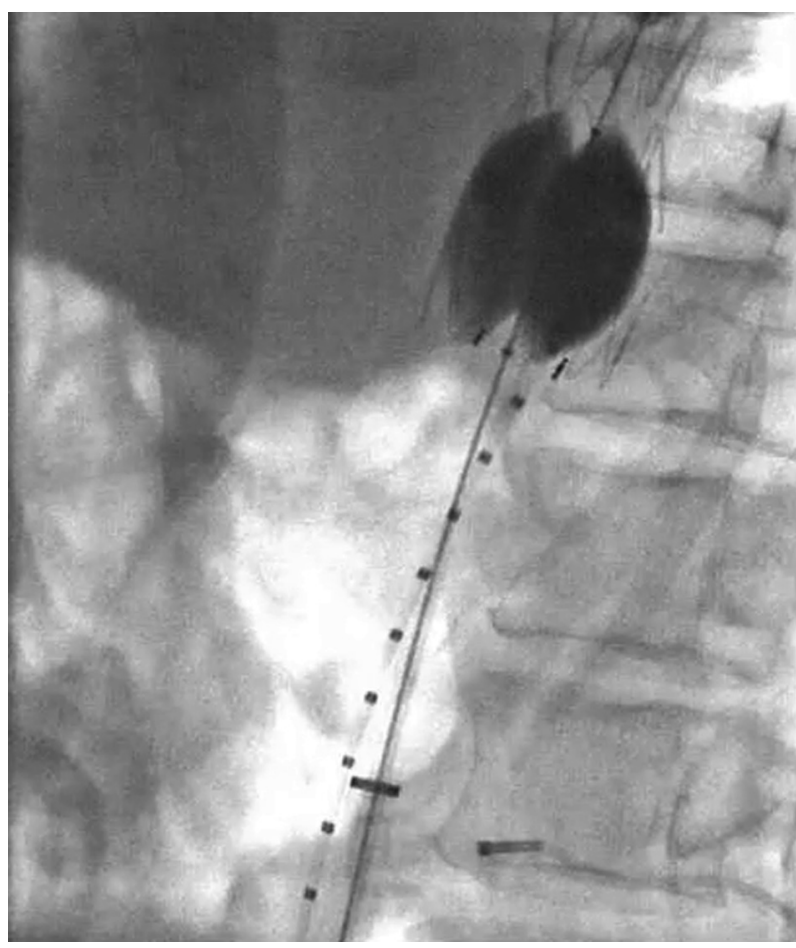

VIDEO 1. Balloon molding of the distal end of the endograft is an essential component of distal landing zone optimization to overcome the disrupted septal remnants and enable secure apposition across the seal zone. Shown here is an example using a Tri-Lobe balloon (GORE). Video available at: https://www.jtcvs.org/article/S0022-5223(18)32028-2/fulltext.
Successful implantation of stent-grafts and associated adjunct interventions was accomplished in all procedures. Aneurysm exclusion was accomplished using commercial thoracic endografts in 16 procedures. The mean number of main aortic devices used per procedure (including main iliac branch components) was $1.7 \pm 0.9$. In patients in whom the distal landing zone was in the visceral aorta, distal seal with visceral preservation was accomplished using SMFSG in 3 procedures and parallel superior mesenteric artery stent-graft in one (Figure 4, Video 2). Adjunct FL obliteration using AMPLATZER plugs plug (St Jude Medical/Abbott, Minneapolis, Minn) was used in 5 procedures. Re-entry tears resulting in major retrograde filling of the FL at the level of the distal iliac bifurcation were present in 3 patients. This was managed with distal extension using an IBE iliac branch device in 3 patients and with obliteration of the FL connections using an AMPLATZER in 1 patient.

One intraprocedural fatality occurred due to aortic tear during wire-pull expansion in a patient with a heavily calcified and tortuous aorta. The patient succumbed to a cardiac arrest despite deployment of the endograft and distal seal with exclusion of the suspected extravasation point. No other deaths occurred in the patient cohort during the follow-up period.

Spinal cord ischemia developed in 1 patient who had preexisting lower-extremity weakness as the result of a previous stroke. She underwent an emergent DLZO procedure
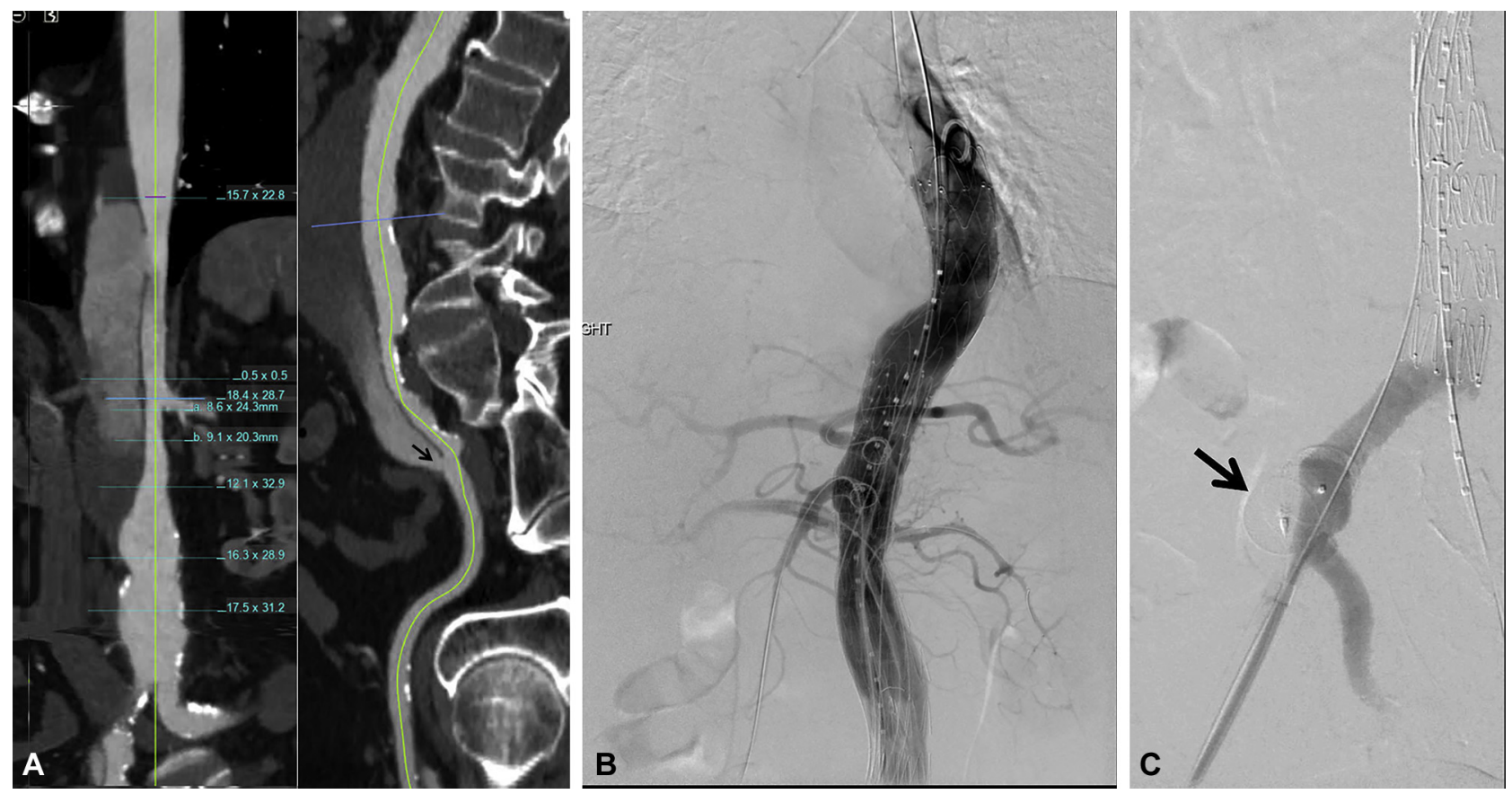

FIGURE 4. A 62-year-old patient with CDAD presenting with an extent-III thoracoabdominal aneurysm, extending into the right iliac bifurcation. A, CTA reconstruction showing a fibrotic septum across the visceral aorta extending to the level of the distal right common iliac artery with a large reentry tear at that level (arrow). B, Broad-based DLZO was performed followed by 4-vessel SMFSG repair, extended proximally with a thoracic aortic endograft. C, Residual retrograde filling at the level of the right common iliac artery bifurcation was excluded with an AMPLATZER plug (arrow). 


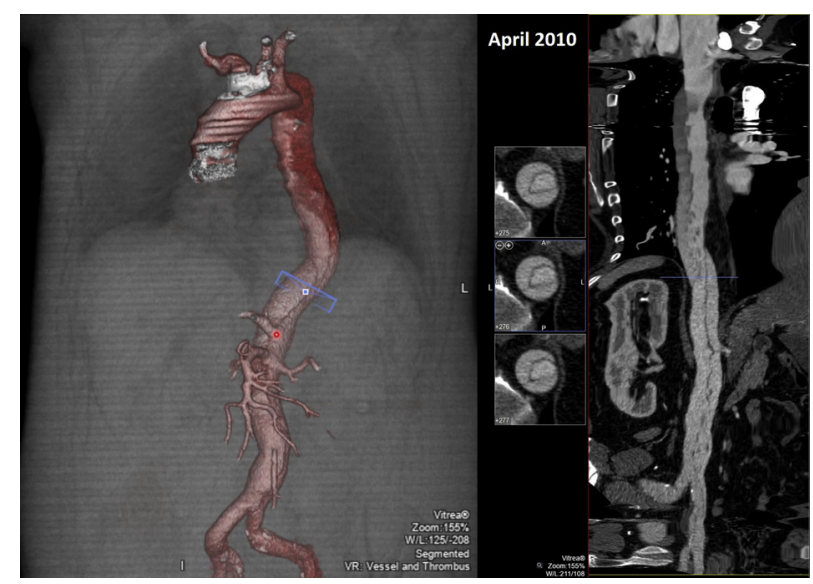

VIDEO 2. Detailed description of the procedure in a patient in whom the landing zone was located in the distal aorta, necessitating fenestrated endograft repair. Video available at: https://www.jtcvs.org/article/S00225223(18)32028-2/fulltext.

without spinal drainage because of an acute presentation. She had worsening of the weakness postoperatively that improved to baseline during hospitalization. Spinal cord imaging showed no evidence of cord ischemia, and no cerebrospinal fluid drainage was performed. Transient azotemia developed in 3 patients and recovered to baseline or better in all. Vocal cord paralysis developed in 1 patient, which was attributed to cranial nerve injury during a subclaviancarotid transposition procedure and resolved spontaneously 2 months later. Brachial artery disruption complicated the delivery of a branch stent graft. This necessitated a vein bypass from the upper to the antecubital brachial artery. Access-site groin hematomas developed in 2 patients who underwent percutaneous access, and all resolved without sequelae with conservative management. Groin wound complications developed in 2 patients, including 1 superficial infection managed with antibiotics and local wound and 1 lymph leak managed with surgical exploration and suture control of leaking lymphatics. Self-limited ileus and/or pancreatitis developed after 2 procedures.

Two of the patients were lost to follow-up after the procedure. Imaging and clinical follow-up were available on 14 patients at a mean delay of $15 \pm 11$ months (range: 1 33). Recurrence or failure of the index procedure was defined as persistent growth of the aneurysm $(\geq 10 \mathrm{~mm}$ at 1 year), and/or progressive dilatation of the seal zone with widening gap between the endograft and aortic wall at the distal seal zone). Delayed failure after the index DLZO procedure was noted in 3 patients, 2 of whom had recurrent pain and accelerated aneurysm enlargement on crosssectional imaging at 8 and 12 months after initial procedure. Distal type 1B endoleak (T1BEL) was identified in both with loss of distal seal (Figure 5). Both underwent repeat DLZO and distal extension to reachieve the seal. A third patient had an asymptomatic distal T1BEL with loss of distal seal, which was managed by further distal extension using a 2-vessel SMFSG (superior mesenteric artery and right renal artery stented fenestrations). Follow-up imaging in all showed resolution of the endoleak and regression of aneurysm sac diameter.

Angiographic T1BEL at the end of the index procedure or on follow-up computed tomography angiography (CTA) was a significant predictor of sac growth $(P<.001)$. Insufficient endograft diameter oversizing was predictive of failure (no recurrence: $14.8 \pm 4.0 \%$ oversizing vs recurrence: $4.2 \pm 3.8 \%$ oversizing, $P=.016)$. Presence of a type-2 endoleak on follow-up imaging was not significantly related to sac growth or reintervention. Neither aortic diameter at the intended seal zone nor endoprosthesis diameter was predictive of recurrence. Delayed failure was not related to the use of any specific endograft or the use of SMFSG, parallel visceral stent-graft, or iliac branched endoprosthesis. There was also no difference between balloon-based versus wire-pull based fenestration augmentation. No patient related variables were significantly related to delayed failure, including sex, age, poorly controlled hypertension, and other medical comorbidities.

\section{DISCUSSION}

Failure of endovascular therapy in CDAD directly relates to persistent retrograde filling of the FL due to suboptimal or incomplete distal seal. ${ }^{22}$ Although a proximal seal can be more readily optimized with the availability of newgeneration stent-grafts and use of partial arch debranching or hybrid procedures, lack of a distal seal zone is often problematic. Less morbid hybrid approaches for distal seal zone optimization have been described, including open aortic fenestration or distal debranching procedures. ${ }^{19,23}$ These approaches, however, continue to suffer from the morbidity of a major abdominal aortic surgery and may not be feasible in complex chronic dissections involving the visceral branches.

Our approach draws on several synergistic strategies to optimize seal at the distal landing zone and promote thrombosis of the FL, collectively coined as DLZO. Central to DLZO is the targeted ablation of the fibrotic septum to allow secure apposition of the endograft distal to the aneurysmal segment, without compromising visceral or lower extremity perfusion (Figure 1). Our preliminary experience suggests a promising role for DLZO for creating a distal landing zone in CDAD before endografting. Our experience also demonstrates the feasibility of managing aneurysmal degeneration extending to the visceral and distal aortoiliac segments with the use of fenestrated and/or branched platforms and supplemental utilization of FL obliteration strategies.

One must be cautious not to generalize our results, which were derived in a small, and carefully selected group of patients. We currently reserve DLZO to patients with 

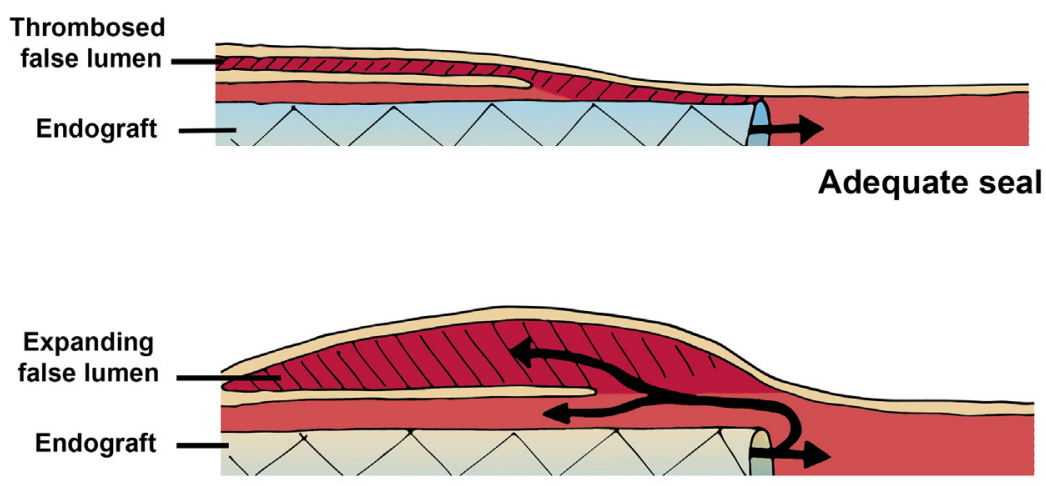

A

Inadequate seal
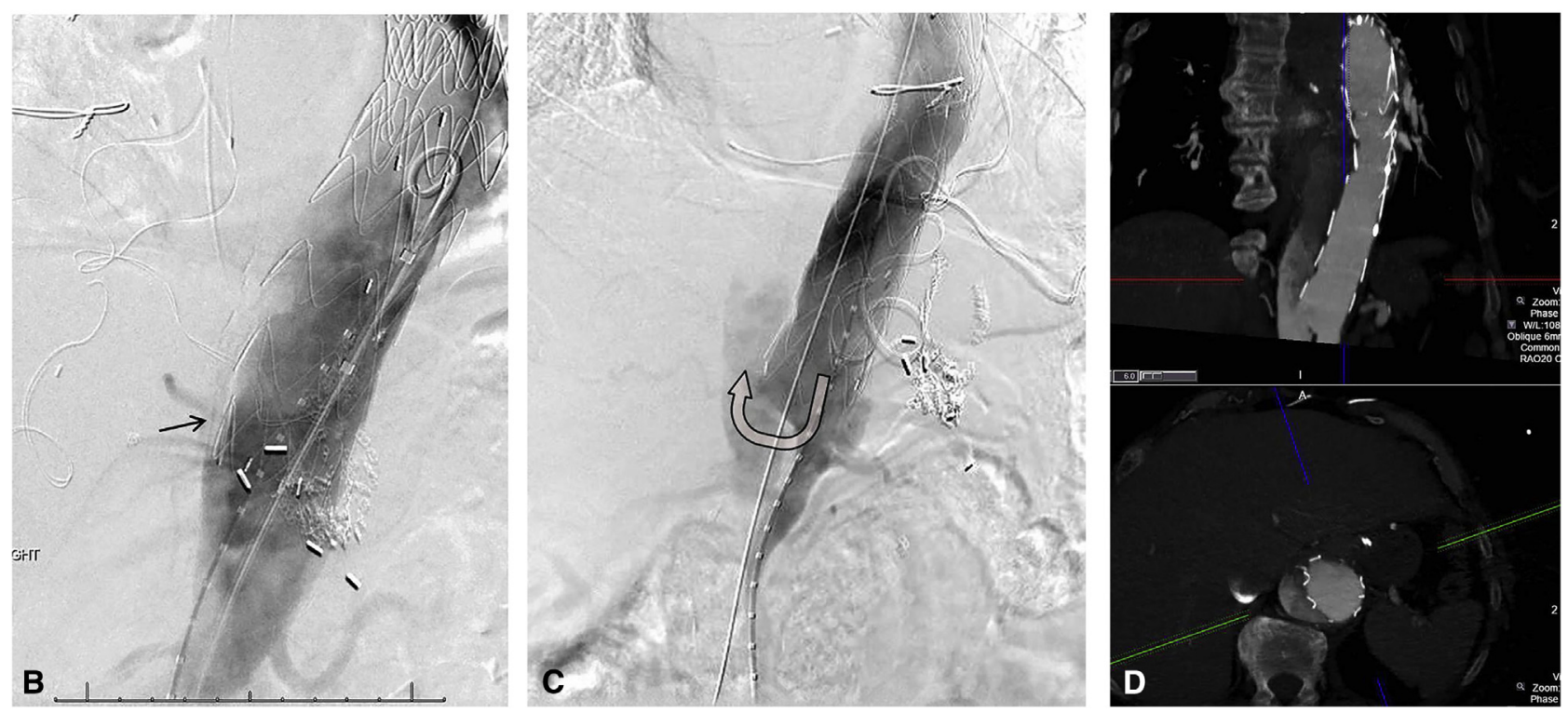

FIGURE 5. Lack of seal can be due to a short seal segment and/or insufficient apposition due to undersized endograft or inadequate balloon molding. A, A serious deleterious consequence of insufficient seal after DLZO is exaggerated pressurization of the FL, resulting in a high-resistance/high-flow pattern, which may promote accelerated sac growth. B, Example of accelerated sac growth after DLZO in a patient with residual T1BEL at the end of the index procedure. Although good graft apposition is achieved across a 10-mm seal segment length, there is a faint T1BEL (arrow). C, This patient developed recurrent symptoms 3 months later, and a CTA was obtained showing unimpeded flow into the FL and $>15$-mm increase in sac diameter. Angiogram before repeat DLZO and distal extension showed considerable widening of the gap between the endograft and aortic wall and extensive retrograde filling of the FL aneurysm (hairpin arrow). The patient underwent repeat DLZO, allowing adequate seal distal to the aneurysm with thrombosis of the aneurysm and resolution of the symptom.

suitable anatomy, which includes a straight landing segment, adequate seal zone length ("parallel walls" length $>20 \mathrm{~mm}$ ). Because of the limit of diameter of available endoprostheses and the need to allow adequate device oversizing, the centerline aortic diameter in the seal zone should ideally be $<42 \mathrm{~mm}$. Septal fenestration is not without risk, as demonstrated in 1 fatality encountered during the wire-slicing fenestration procedure. Caution should be exerted in patients with hostile anatomy, extreme tortuosity, excessive thrombosis, and heavy calcification. Attention must also be paid to access-related challenges, as involvement of the iliac segments with the dissection is common. This requires careful assessment of preoperative cross-sectional imaging and reliance of IVUS for localization during the procedure.

Adoption of available fenestrated and branch endograft technology allows the seal zone to be located further distally, into the visceral aortic segment or even at the level of the distal iliac bifurcation. Although the latter has been facilitated by the commercial availability of iliac branch device, SMFSG remains an invaluable adjunct to allow seal in the visceral aorta. Although the use of fenestrated/ branched stent-graft devices has been well described in CDAD with aneurysmal degeneration, ${ }^{24}$ the technique can 
be challenging in the presence of a chronic septum, limited TL working space, and difficult alignment of the fenestrations with the visceral branches. We have found that combining DLZO to achieve broad obliteration of the intervening septum in the visceral aorta can greatly facilitate the process of branch cannulation and stenting through the fenestrations (Figure 4).

Our experience suggests that ensuring a sufficient length of relatively nonaneurysmal distal seal zone is crucial for the prevention of delayed failure. Residual retrograde filling of the FL appeared to be a marker of procedure failure; angiographically faint T1BEL after the procedure should be addressed or carefully monitored. Suboptimal distal seal can have serious implications due to persistent filling of the FL which, if not addressed in a timely manner, can result in incremental deterioration of distal seal and pressurization of the FL with accelerated aneurysm growth (Figure 5). Loss of distal seal was encountered in 3 patients in our experience, which was symptomatic with recurrent back pain in 2. Sufficient optimized distal seal segment length, selection of a sufficiently oversized endograft relative to the optimized lumen (10\%-20\%), and optimal balloon molding of the endograft at the seal zone are essential to achieve secure seal (Video 1). DLZO should be reserved for patients in whom an optimizable distal seal zone is achievable (straight seal zone length $\geq 20 \mathrm{~mm}$ and optimized aortic diameter $\leq 42 \mathrm{~mm}$ ).

As mentioned, even a faint residual T1EL at the end of procedure poses a significant risk for subsequent dissociation of the distal seal with accelerated sac growth. In such cases, short-term follow-up is highly recommended, and reintervention must be considered to achieve complete seal. There may be a merit for considering adjunct FL obliteration in patients with residual filling of the FL after deployment of the endograft. Although our limited experience did not allow us to evaluate the effect of pre-emptive FL obliteration during the index procedure, device-mediated FL occlusion has been suggested to play an important role in achieving FL thrombosis. ${ }^{25}$ We have found the adjunct use of FL plug obliteration to be useful in the management of 2 of 3 recurrences in our series. However, the role of FL obliteration during the index DLZO procedure should be assessed in a head-to-head study.

The importance of follow-up imaging cannot be overstated. CTA is recommended every 6 months until stability of the repair is ascertained, after which the frequency of imaging may be lowered. Although contrast-enhanced CTA is the most effective follow-up modality, magnetic resonance imaging can also be used. Nonenhanced computed tomography can also be valuable in assessing sac size and loss of apposition between the stent-graft and aortic wall at the seal zone.

In conclusion, the most common cause for incomplete exclusion of aneurysmal pathology in CDAD is lack of sufficient distal seal, which is due to a short and hostile distal landing zone preventing secure apposition. The described DLZO approach can enable distal seal in challenging CDAD.

\section{Conflict of Interest Statement}

Mel J. Sharafuddin reports IDE research grant support as PI from Bolton, Gore, Terumo, and Cook outside the submitted work. All other authors have nothing to disclose with regard to commercial support.

\section{References}

1. Hiratzka LF, Bakris GL, Beckman JA, Bersin RM, Carr VF, Casey DE Jr, et al. $2010 \mathrm{ACCF} / \mathrm{AHA} / \mathrm{AATS} / \mathrm{ACR} / \mathrm{ASA} / \mathrm{SCA} / \mathrm{SCAI} / \mathrm{SIR} / \mathrm{STS} / \mathrm{SVM}$ guidelines for the diagnosis and management of patients with thoracic aortic disease. J Am Coll Cardiol. 2010;55:e27-129.

2. Estrera AL, Miller CC, Safi HJ, Goodrick JS, Keyhani A, Porat EE, et al. Outcomes of medical management of acute type B aortic dissection. Circulation. 2006;114(1 suppl):I384-9.

3. Tefera G, Acher CW, Hoch JR, Mell M, Turnipseed WD. Effectiveness of intensive medical therapy in type B aortic dissection: a single-center experience. $J$ Vasc Sur. 2007;45:1114-9.

4. Sabik JF, Lytle BW, Blackstone EH, McCarthy PM, Loop FD, Cosgrove DM Long-term effectiveness of operations for ascending aortic dissections. J Thorac Cardiovasc Surg. 2000;119:946-64.

5. Zierer A, Voeller RK, Hill KE, Kouchoukos NT, Damiano RJ Jr, Moon MR Aortic enlargement and late reoperation after repair of acute type A aortic dissection. Ann Thorac Surg. 2007;84:479-87.

6. Subramanian S, Roselli EE. Thoracic aortic dissection: long-term results of endovascular and open repair. Semin Vasc Surg. 2009;22:61-8.

7. Nienaber CA, Kische S, Rousseau H, Eggebrecht H, Rehders TC, Kundt G, et al Endovascular repair of type B aortic dissection: long-term results of the Randomized Investigation of Stent Grafts in Aortic Dissection Trial. Circ Cardiovasc In terv. 2013;6:407-16.

8. Sailer AM, Nelemans PJ, Hastie TJ, Chin AS, Huininga M, Chiu P, et al. Prognostic significance of early aortic remodeling in acute uncomplicated type B aortic dissection and intramural hematoma. J Thorac Cardiovasc Surg. 2017; 154:1192-200

9. Liu F, Ge YY, Guo W, Liu XP, Jia X, Xiong J, et al. Preoperative thoracic false lumen branches are predictors of aortic enlargement after stent grafting for DeBakey IIIb aortic dissection. J Thorac Cardiovasc Surg. 2018; 155:21-9.e3.

10. Famularo M, Meyermann K, Lombardi JV. Aneurysmal degeneration of type B aortic dissections after thoracic endovascular aortic repair: a systematic review. $J$ Vasc Surg. 2017;66:924-30.

11. Afifi RO, Sandhu HK, Leake SS, Boutrous ML, Kumar V III, Azizzadeh A, et al Outcomes of patients with acute type B (DeBakey III) aortic dissection. Circulation. 2015;132:748-54.

12. Durham CA, Cambria RP, Wang LJ, Ergul EA, Aranson NJ, Patel VI, et al. The natural history of medically managed acute type B aortic dissection. J Vasc Surg. 2015;61:1192-9.

13. Fattori R, Montgomery D, Lovato L, Kische S, Di Eusanio M, Ince H, et al. Survival after endovascular therapy in patients with type B aortic dissection: a report from the International Registry of Acute Aortic Dissection (IRAD). JACC: Cardiovasc Interv. 2013;6:876-82.

14. Parsa CJ, Schroder JN, Daneshmand MA, McCann RL, Hughes GC. Midterm results for endovascular repair of complicated acute and chronic type B aortic dissection. Ann Thorac Surg. 2010;89:97-102; discussion 102-104.

15. Andacheh ID, Donayre C, Othman F, Walot I, Kopchok G, White R. Patient outcomes and thoracic aortic volume and morphologic changes following thoracic endovascular aortic repair in patients with complicated chronic type B aortic dissection. J Vasc Surg. 2012;56:644-50.

16. Nauta FJ, Trimarchi S, Kamman AV, Moll FL, van Herwaarden JA, Patel HJ, et al. Update in the management of type B aortic dissection. Vasc Med. 2016; 21:251-63.

17. Schumacher H, Von Tengg-Kobligk H, Ostovic M, Henninger V, Ockert S Böckler D, et al. Hybrid aortic procedures for endoluminal arch 
replacement in thoracic aneurysms and type B dissections. J Cardiovasc Surg. 2006;47:509.

18. Hanna JM, Andersen ND, Ganapathi AM, McCann RL, Hughes GC. Five-year results for endovascular repair of acute complicated type B aortic dissection. $J$ Vasc Surg. 2014;59:96-106.

19. Geroulakos G, Zambas N. Debranching of the aorta produces thrombosis of the false lumen in selected cases of chronic type A aortic dissection. Int Angiol. 2009; 28:79-81.

20. Roselli EE. Optimization of distal landing zone for TEVAR in chronic dissection. Ann Cardiothorac Surg. 2014;3:329-32.

21. Sharafuddin MJ, Hoballah JJ, Kresowik TF, Nicholson RM, Sharp WJ. Impact of aggressive endovascular recanalization techniques on success rate in chronic total arterial occlusions (CTOs). Vasc Endovasc Surg. 2010;44:460-7.

22. Khoynezhad A, Toluie S, Al-Atassi T. Treatment of the chronic type B aortic dissection: the pro-endovascular argument. Semin Thorac Cardiovasc Surg. 2017;29:131-6.
23. Roselli EE, Sepulveda E, Pujara AC, Idrees J, Nowicki E. Distal landing zone open fenestration facilitates endovascular elephant trunk completion and false lumen thrombosis. Ann Thorac Surg. 2011;92:2078-84.

24. Kitagawa A, Greenberg RK, Eagleton MJ, Mastracci TM, Roselli EE. Fenestrated and branched endovascular aortic repair for chronic type B aortic dissection with thoracoabdominal aneurysms. J Vasc Surg. 2013; 58:625-34.

25. Marone EM, Leopardi M, Bertoglio L, Mascia D, Chiesa R. Original off-label endovascular solution to occlude false lumen rupture in chronic type B aortic dissection. Ann Vasc Surg. 2017;40:299.e1-5.

Key Words: chronic aortic dissection, septal fenestration, endoleak, thoracic endovascular aortic repair, fenestrated stent-grafts 